\title{
Erilaisten karsinaratkaisujen vaikutus kasvavien lihanautojen tuotantoon ja hyvinvointiin
}

\author{
Leena Tuomisto ${ }^{1)}$, Arto Huuskonen ${ }^{1)}$, Leena Ahola ${ }^{2)}$, Jaakko Mononen ${ }^{2)}$, Risto Kauppinen ${ }^{3)}$, ja Paula \\ Martiskainen $^{2)}$ \\ ${ }^{1)}$ Maa- ja elintarviketalouden tutkimuskeskus, Pohjois-Pohjanmaan tutkimusasema, Tutkimusaseman- \\ tie 15,92400 Ruukki.etunimi.sukunimi@mtt.fi \\ ${ }^{2)}$ Kuopion yliopisto, Soveltavan biotekniikan instituutti, PL 1627, 70211 Kuopio. etuni- \\ mi.sukunimi@uku.fi \\ ${ }^{3}$ Savonia-ammattikorkeakoulu, Maaseutuala, PL 72, 74101 Iisalmi.risto.kauppinen@savonia-amk.fi
}

\section{Tiivistelmä}

Tämän kirjallisuuskatsauksen tarkoituksena oli selvittää erilaisten karsinaratkaisujen vaikutusta kasvavien lihanautojen tuotantoon ja hyvinvointiin. Useimpien kasvatuskokeiden perusteella karsinan pohjamateriaalilla ei ole vaikutusta lihanautojen kasvuun, rehunkäyttöön, rehuhyötysuhteeseen tai ruhon ja lihan laatuun. Lihanaudoilla esiintyy enemmän käyttäytymisongelmia rakolattialla kuin päällystetyillä lattioilla (olkipohja, kumipäällysteet), mikä johtuu rakolattian kovasta ja liukkaasta pinnasta. Erityisesti makuulle asettuminen ja ylös nouseminen vaikeutuvat. Lisäksi rakolattialla eläimet liukastelevat ja voivat jopa vältellä tasapainoa vaativia toimintoja.

Yleisesti lihanaudoilla näyttäisi olevan enemmän terveysongelmia rakolattialla kuin muilla lattiamateriaaleilla. Häntävauriot, ontuminen ja polvinivelien kasvuhäiriöt vaivaavat lihanautoja useammin rakolattialla kuin olkipohjalla. Ontuminen ja kasvuhäiriöt näyttäisivät kuitenkin olevan ongelma myös vinolla pohjalla. Pehmeällä alustalla sorkat eivät kulu yhtä paljon kuin kovemmalla alustalla ja voivat sen seurauksena kasvaa pitkiksi. Kiinteällä lattialla ongelmia aiheuttaa lattialle kerääntyvä liete, joka voi syövyttää sorkkaa ja aiheuttaa bakteeritulehduksia.

Preferenssikokeissa naudat ovat selvästi osoittaneet, että ne makaavat mieluummin pehmeällä kuin kovalla alustalla. Tämä on ymmärrettävää, koska naudat ovat alun perin sopeutuneet makaamaan joustavalla alustalla luontaisessa elinympäristössään, ruohotasangolla. Preferenssikokeiden perusteella rakolattia on lihanautojen mielestä kaikkein epämiellyttävin pohjamateriaali, jota eläimet todennäköisesti karttavat sen liukkauden ja kovuuden vuoksi. Pehmeä alusta sen sijaan tarjoaa sorkalle pitävämmän pohjan ja vartalon muotoja mukailevan pinnan eläimen maatessa.

Tutkimustulosten perusteella lihanautojen hyvinvointia voidaan parantaa tarjoamalla niille mahdollisuus maata pehmeällä alustalla. Tämä voidaan toteuttaa kuivittamalla osa karsinasta makuualueeksi tai vaihtoehtoisesti päällystämällä osa palkeista kumipäällysteellä. Kiinteitä lattioita ja kuivikkeita käytettäessä lattian puhdistuksesta ja kuivikkeiden riittävästä käytöstä on tärkeää huolehtia eläinten puhtauden ja sorkkaterveyden vuoksi. Sorkkien kasvun hillitsemiseksi karsinaan tulisi sijoittaa myös kovapohjaisia alueita. Jalkaongelmien vähentämiseksi vinopohjan kaltevuus tulisi olla korkeintaan 10 prosenttia.

Asiasanat: kotieläintuotanto, naudanlihantuotanto, naudat, lihakarja, tuotantoympäristö, käyttäytyminen, hyvinvointi, karsinat, lattiat, pohjat, materiaalit 


\section{Johdanto}

Lihanautojen yleisin kasvatusympäristö on ryhmäkarsina. Tämän kirjallisuuskatsauksen tarkoituksena oli selvittää erilaisten karsinaratkaisujen vaikutusta kasvavien lihanautojen tuotantoon ja hyvinvointiin. Tässä kirjallisuuskatsauksessa rakolattiasta puhuttaessa tarkoitetaan betonipalkeista valmistettua, päällystämätöntä rakolattiaa, ellei rakolattian laatua ole toisin määritelty.

\section{Karsinaratkaisuja koskevat eläinsuojelusäädökset}

Eläinsuojelusäädöksissä määrätään, että eläinsuojan lattia ei saa olla liukas ja se on voitava pitää helposti kuivana (MMMA 7.6.1996/396). Eläinsuojan lattian on oltava sellainen, että nestemäiset eritteet poistuvat asianmukaisesti tai imeytyvät hyvin kuivikkeisiin (MMMp 23.5.1997/14/EEO/1997). Tarvittaessa nautojen makuualue on kuivitettava. Rakolattian, ritilälattiaan tai muun rei'itetyn lattian on oltava sellainen, että nautojen sorkat eivät tartu kiinni tai muutoin vahingoitu. Kylmäpihatossa osa pohjasta on kuivitettava makuualueeksi (MMMA 3.6.2002/6/EEO/2002). Ympärivuotisessa ulkotarhakasvatuksessa eläimillä on oltava käytössään kuivitettu makuualue suojarakennuksen sisällä. Alle kaksiviikkoisella vasikalla on oltava hyvin kuivitettu makuupaikka (MMMp 23.5.1997/14/EEO/1997). Eläinsuojelusäädöksissä on myös esitetty suosituksia rakolattian betonipalkkien ja niiden väliin jäävien rakojen leveydestä (palkin leveys 7,0-12,5 cm ja raon leveys 3,0-4,0 cm naudan iästä riippuen).

\section{Pohjamateriaalin vaikutus tuotantoon}

Useimpien tutkimusten perusteella pohjamateriaalin laadulla ei ole suurta vaikutusta lihanautojen kasvuun, rehunkulutukseen, rehuhyötysuhteeseen tai ruhon ja lihan laatuun, kun vertailut on tehty samassa eläintiheydessä. Hickeyn ym. (2003) kokeessa karsinan pohjamateriaalilla (rakolattia tai olkipohja) ei ollut vaikutusta härkien kasvuun, rehunkulutukseen, rehuhyötysuhteeseen tai ruhon laatuun. Andersenin ym. (1991) kokeessa pohjamateriaalilla ei ollut vaikutusta sonnien kasvuun, rehunkulutukseen, rehuhyötysuhteeseen tai ruhon ja lihan laatuun, mutta olkipohjalla kasvaneiden eläinten teurasprosentti oli hieman pienempi kuin rakolattialla kasvaneilla eläimillä. Gottardon ym. (2003) kokeessa karsinan pohjamateriaalilla (rakolattia tai olkipohja) ei ollut vaikutusta sonnien kasvuun, rehunkulutukseen, rehuhyötysuhteeseen tai ruhon ja lihan laatuun. Hindheden ym. (1996) kokeessa karsinan pohjamateriaalilla (rakolattia tai osittain kuivitettu rakolattia) ei ollut vaikutusta hiehojen kasvuun, rehunkulutukseen tai rehuhyötysuhteeseen.

Ruis-Heutinck ym. (2000) tutkivat kolmea erilaista karsinatyyppiä: ensimmäisen karsinan pohja oli kokonaan rakolattiaa, toisen karsinan pohja oli rakolattiaa, jonka palkeista osa oli päällystetty kumilla makuualueeksi ja kolmannen karsinan pohja oli betonilattiaa, josta osa oli kuivitettu makuualueeksi. Pohjamateriaalilla ei ollut vaikutusta sonnien rehunkulutukseen, mutta eläimet kasvoivat paremmin ja olivat loppupainoltaan suurempia rakolattiapohjaisessa karsinassa, jonka palkeista osa oli kumipäällysteisiä kuin osittain olkipohjaisessa karsinassa. Rakolattialla kasvaneet sonnit eivät näiltä osin eronneet muista ryhmistä. Lowen ym. (2001b) kokeessa härkiä kasvatettiin karsinoissa, joiden pohja oli rakolattiaa, rei'itetyllä kumimatolla päällystettyä rakolattiaa, kumimattosuikaleilla päällystettyä rakolattiaa tai olkipohjaa. Pohjamateriaalilla ei ollut vaikutusta härkien kasvuun, rehunkulutukseen tai ruhon ja lihan laatuun.

Ruotsalaisissa tutkimuksissa Mossberg ym. $(1992,1993)$ vertasivat sonnivasikoiden ja sonnien tuotantoa lämpimässä rakennuksessa rakolattiapohjaisissa karsinoissa ja kylmäpihatossa tilavammissa, osittain kuivitetuissa betonipohjaisissa karsinoissa. Karsinatyypillä ei ollut vaikutusta vasikoiden kasvuun, rehunkulutukseen, rehuhyötysuhteeseen tai ruhon rasvaisuuteen, mutta vasikoiden teurasprosentti oli suurempi olkipohjalla kuin rakolattialla (Mossberg ym. 1992). Karsinatyypillä ei ollut vaikutusta sonnien kasvuun, rehunkulutukseen tai rehuhyötysuhteeseen, mutta kylmäpihatossa sonnien ruhoihin kerääntyi vähemmän rasvaa kuin rakolattialla (Mossberg ym. 1992, 1993). Lisäksi toisessa kokeessa sonnien teurasprosentti oli suurempi kylmäpihatossa kuin rakolattialla (Mossberg ym. 1993). Kylmäpihaton sonnien vähäisemmän rasvoittumisen Mossberg ym. (1992, 1993) esittivät olevan seurausta kylmäpihaton karsinoiden alhaisemmasta eläintiheydestä ja pitävämmästä lattiamateriaalista (osittain kuivitettu betonipohja), minkä vuoksi eläimet mahdollisesti olivat aktiivisempia kuin rakolattialla. Liikunnan seurauksena pihaton sonnit kuluttivat enemmän energiaa ja niihin kerääntyi enemmän lihaskudosta ja vähemmän rasvakudosta kuin rakolattialla kasvaneilla eläimillä. 


\section{Pohjamateriaalin vaikutus käyttäytymiseen}

\section{Makuukäyttäytyminen}

Tutkimuksissa naudoilla on havaittu vaikeuksia makuulle asettumiseen ja ylösnousuun liittyvien liikesarjojen suorittamisessa erityisesti rakolattialla. Sonneilla on havaittu enemmän keskeytyneitä makuulle asettumisen yrityksiä (Andreae ja Smidt 1982, Lidfors 1992) ja epänormaaleja makuulleasettumisia takapää tai etupää edellä (Graf 1979, Ruis-Heutinck ym. 2000) rakolattialla kuin olkipohjalla. Sonnien on myös havaittu suorittavan liikesarjat useammin epänormaalisti tavallisella rakolattialla kuin kumipäällysteisillä palkeilla (Smits ym. 1994, Ruis-Heutinck ym. 2000). Ruis-Heutinckin ym. (2000) kokeessa sonnit (ikä 16,5 kk) suorittivat rakolattialla 72-87 \% ylösnousuista ja 70-90 \% makuulleasettumisista epänormaalisti. Päällystetyillä lattioilla (olkipohja, kumipäällysteiset palkit) vain 5-9 \% ylösnousuista ja 1-7 \% makuulleasettumisista suoritettiin epänormaalisti. Rakolattian liukkaan ja kovan pinnan on esitetty olevan syynä nautojen vaikeuksiin liikesarjojen suorittamisessa (Graf 1979, Jensen ym. 1995).

Sonnien on havaittu asettuvan makuulle ja nousevan ylös harvemmin rakolattialla kuin olkipohjalla (Graf 1979, Lidfors 1992, Ruis-Heutinck ym. 2000). Ladewigin (1987) mukaan eläimet asettuvat makuulle olkipohjalla vuorokaudessa 15-25 kertaa, mutta rakolattialla toiminto vähenee 6-12 kertaan. Myös Andersen ym. (1991) ja Jensen ym. (1995) havaitsivat nautojen makuujaksojen lukumäärän vähentyvän rakolattialla verrattuna kokonaan tai osittain kuivitettuun lattiaan. Asennon vaihtamisen harventuessa eläimet makaavat yhtäjaksoisesti pidempään (Graf 1979).

\section{Muu käyttäytyminen}

Erityisesti rakolattialla lihanautojen on havaittu liukastelevan tasapainoa vaativien toimintojen, kuten turkin hoidon, sosiaalisten toimintojen ja astumisyritysten yhteydessä (Ming 1984, Smits ym. 1994) Mahdollinen liukastumisvaara rakolattialla näyttäisi jopa vähentävän joidenkin toimintojen määrää. Ruis-Heutinckin ym. (2000) kokeessa sonnit venyttelivät makuulta noustuaan harvemmin kumipäällysteisillä palkeilla tai rakolattialla kuin olkipohjalla. Lisäksi sonneilla on havaittu vähemmän astumisyrityksiä rakolattialla kuin olkipohjalla (Andersen ym. 1991) tai osittain päällystetyillä lattioilla (kumipäällysteiset palkit, olki) (Ruis-Heutinck ym. 2000). Karsinan pohjamateriaalilla ei useimmissa kokeissa ole havaittu vaikutusta stereotyyppisen käyttäytymisen, toisen eläimen puskemisen, toisen eläimen haistelun/nuolemisen tai turkin hoidon määrään (Gottardo ym. 2003, Hickeyn ym. 2003, Lowe ym. 1999)

\section{Pohjamateriaalin vaikutus terveyteen}

\section{Stressifysiologia ja immunologia}

Lihanautojen kortisolieritystä mittaamalla on saatu viitteitä, että makuulle asettuminen aiheuttaisi enemmän stressiä rakolattialla kuin olkipohjalla (kts. Ladewig 2000, long-term intermittent stress) (Ladewig 1987, Unselm ym. 1982). Karsinan pohjamateriaalin ei ole havaittu vaikuttavan lihanautojen immuunijärjestelmän toimintaan tai veren ominaisuuksiin (Hickey ym. 2003, Gottardo ym. 2003).

\section{Muu terveys}

Murphyn ym. (1987) havaitsivat irlantilaisilla tiloilla lihanautojen sairastuvuuden olevan suurempi rakolattialla (9,73 \% eläimistä) kuin olkipohjalla (5,42 \%) kasvaneilla eläimillä. ITEBin (1983) selvityksessä sonnien kuolleisuuden ja ennenaikaisten poistojen määrän todettiin olevan pienin olkipohjalla (1,95 \% eläimistä), seuraavaksi pienin vinopohjalla (4,32 \%) ja suurin rakolattialla (5,99 \%). Sundrumin ja Rubelowskin (2001) mukaan saksalaisilla lihanautatiloilla eläimiä menetettiin kesken kasvatuskauden useammin rakolattialla (2,3 \% eläimistä) kuin olkipohjaisissa kasvatusympäristöissä (1,2 \%). Murphyn ym. (1987) selvityksen mukaan irlantilaisilla tiloilla lihanaudoilla esiintyi ontumista enemmän rakolattialla (4,75 \% eläimistä) kuin olkipohjalla (2,43 \%). Lisäksi rakolattialla suurempi osa ontumistapauksista oli vakavia. ITEBin (1983) selvityksen mukaan liharotuisia sonneja hoidettiin jalkaongelmien vuoksi eniten vinopohjalla (36 \% eläimistä), seuraavaksi eniten rakolattialla (26 \%) ja vähiten olkipohjalla (14\%). 
Rakolattialla liikkuessaan naudat eivät pysty välttelemään rakoja ja astumaan vain palkkien päälle (Kirchner ja Boxberger 1987). Rakoihin liukastumisen riski kasvaa rakojen suurentuessa (Boxberger 1983). Kirchner ja Boxberger (1987) esittivät, että lihanaudoilla palkkien välisen raon leveys saisi olla korkeintaan 20-25 mm. Haidnin (1987) mukaan raon leveys saisi lihanaudoilla olla korkeintaan 19 mm kasvatuksen alussa ja 28 mm kasvatuksen lopussa.

Hindheden ym. (1996) kokeessa hiehoilla havaittiin enemmän kantasyöpymää rakolattialla kuin osittain kuivitetussa karsinassa. Andersenin ym. (1991) kokeessa sonneilla esiintyi enemmän sorkkamätää rakolattialla kuin olkipohjaisessa karsinassa. Useissa tutkimuksissa lihanautojen sorkat kasvoivat pidemmiksi osittain/kokonaan kuivitetuissa karsinoissa kuin kokonaan rakolattiapohjaisessa karsinassa (Andersen ym. 1991, Hindhede ym. 1996, Lowe ym. 2000). Lowen ym. (2000) kokeessa härillä esiintyi voimakkaampaa kantasyöpymää olkipohjalla kuin rakolattialla tai kumimattosuikaleilla tai rei’itetyllä kumimatolla päällystetyllä rakolattialla. Mossbergin (1992) kokeessa sonneja hoidettiin useammin sorkkavälin ajotulehduksen vuoksi osittain kuivitetuissa, kiinteäpohjaisissa karsinoissa kuin rakolattialla.

Tutkimusten perusteella kova rakolattia näyttäisi altistavan nautojen niveliä ja kasvulevyjä vaurioille. Dämmrich (1974) havaitsi vakavampia vaurioita sonnien nivelissä rakolattialla kuin kiinteällä betonipohjalla tai olkipohjalla kasvaneilla eläimillä. Smits ym. (1994) löysivät enemmän vakavia vaurioita etupolvien nivelistä rakolattialla kuin kumipäällysteisillä palkeilla kasvaneilta sonneilta. Myös juottovasikoilla on havaittu enemmän etupolvien nivelvaurioita rakolattialla kuin kumipäällysteisillä palkeilla (Smits ja Wierenga 1991). Ruis-Heutinckin ym. (2000) tutkivat kolmessa erilaisessa karsinassa kasvaneiden sonnien etupolvia. Vakavia etupolven nivelvaurioita löytyi eniten (51 \% eläimistä) rakolattialla, seuraavaksi eniten (36 \%) betoni-pohjaisissa, osittain kuivitetuissa karsinoissa ja vähiten (27 \%) rakolattialla, jonka palkeista osa oli kumipäällysteisiä. Kaikkiaan eriasteisia etupolven nivelvaurioita löytyi 75 prosentilla tutkitusta 134 sonnista. Ruis-Heutinck ym. (2000) arvelivat osittain kuivitetussa karsinassa mm. karsinan pohjan korkeuserojen (kasvava kuivikekerros) lisäävän etupolviin kohdistuvaa painetta, mikä saattoi selittää polvivaurioiden korkeaa esiintyvyyttä kyseisessä karsinatyypissä.

Dumelowin (1993) kokeessa sonnien (220 kg) jalkaterveyttä verrattiin kolmessa erilaisessa rakolattiapohjaisessa karsinassa kolmen kuukauden ajan. Yhden karsinan pohja oli kokonaan rakolattiaa, toisen karsinan pohjasta puolet oli korvattu kaltevalla kiinteällä betonilattialla ja kolmannen karsinan pohjasta $3 / 4$ oli kaltevaa kiinteää betonilattiaa ja vain $1 / 4$ rakolattiaa. Etupolvien ja kintereiden turvotusta sekä ihon ja ihonalaiskerroksen paksuuntumista esiintyi eniten kokonaan rakolattiapohjaisessa karsinassa (noin 70 \% jaloista), seuraavaksi eniten puoliksi betonipohjaisessa karsinassa (noin 40 \%) ja vähiten $3 / 4$ betonipohjaisessa karsinassa (noin $20 \%$ ).

Häntävaurioita esiintyy enemmän rakolattialla kuin muilla pohjamateriaaleilla kasvatetuilla eläimillä (Drolia ym. 1990, Madsen 1987). Schrader ym. (2001) löysivät märkiviä tai nekroottisia häntävaurioita rakolattialla kasvaneilta sonneilta, mutta eivät olkipohjalla kasvaneilta sonneilta. Lieviä ihomuutoksia havaittiin myös olkipohjalla, mutta kuitenkin vähemmän kuin rakolattialla kasvatetuilla sonneilla. Häntävaurioiden vähäisemmän esiintymisen olkipohjalla pääteltiin johtuvan olkipohjan pehmeästä pinnasta, joka antaa periksi hännän jäädessä sorkan alle estäen vakavamman ruhjoutumisen, päinvastoin kuin kova, joustamaton ja teräväreunainen rakolattia. Myös karsinan muodon on esitetty voivan vaikuttaa häntävaurioiden syntyyn. Sonnit suosivat makaamiseen karsinan takaosaa sekä rakolattiapohjaisessa, että syvemmässä, osittain kuivitetussa kiinteäpohjaisessa karsinassa (Lidfors 1992). Jos karsina on muodoltaan syvä ja siinä erottuu selvä takaosan makuualue ja etuosan ruokailualue, lepäävät naudat voivat hakeutua suojaan aktiivisten eläinten jaloista.

\section{Pohjamateriaalin vaikutus eläinten puhtauteen}

Monissa tutkimuksissa lihanaudat ovat olleet puhtaampia olkipohjalla kuin rakolattialla (Andersen ym. 1991, Hickey ym. 2003, Lowe ym. 2001b). Näissä kokeissa olkea käytettiin päivittäin nautaa kohden noin 5-6 kg eläinten ollessa noin 450-600 kg painoisia. Dumelowin (1993) kokeessa sonnit olivat sitä likaisempia mitä suurempi osa (0, 50 tai $75 \%$ ) rakolattiapohjaisen karsinan pohjasta oli korvattu kaltevalla, kiinteällä betonilattialla. 


\section{Nautojen mieltymys eri pohjamateriaaleihin}

Useiden preferenssikokeiden perusteella naudat makaavat mieluummin pehmeällä kuin kovalla alustalla (Herlin 1997, Irps 1987, Manninen ym. 2002). Lowe ym. (2001a) tutkivat härkien mieltymyksiä erilaisiin pohjamateriaaleihin. Pareittaisvertailut tehtiin rakolattian, rei'itetyllä kumimatolla peitetyn rakolattian, sahanpurulla kuivitetun kiinteän lattian ja oljella kuivitetun kiinteän lattian välillä. Härät suosivat makaamiseen eri pohjamateriaaleja seuraavassa järjestyksessä mieluisimmasta alkaen: oljella kuivitettu lattia, sahanpurrulla kuivitettu lattia, rei'itetyllä kumimatolla päällystetty rakolattia ja pelkkä rakolattia. Seisomisen suhteen härkien mieltymykset eivät olleet yhtä ehdottomia: kumimatto ja olkipohja olivat mieluisampia kuin rakolattia, ja olki-pohja oli mieluisampi kuin kumimatto. Kokeen lopuksi härät saivat valita rei’itetyllä kumimatolla päällystetyn rakolattian ja kumimattoliuskoilla päällystetyn rakolattian välillä, mutta eivät suosineet kumpaakaan materiaalia enemmän kuin toista.

Monien seikkojen on esitetty vaikuttavan nautojen mieltymyksiin eri pohjamateriaaleihin. Lowe ym. (2001a) päättelivät tärkeimmän valintaan vaikuttavan tekijän olevan alustan miellyttävyyden eläimen ollessa makuuasennossa. Kun alustan pinta on joustava, nauta välttyy makuuasennossa ulkoneviin luihin kohdistuvalta kivuliaalta paineelta (Irps 1983). Lisäksi valintaan vaikuttaviksi tekijöiksi on esitetty alustan miellyttävyyttä seistessä sekä alustan pitävyyttä sorkan alla (Lowe ym. 2001a). Kuivitettu lattia tarjoaa naudalle pehmeän makuualustan lisäksi pitävän pohjan seisoa ja liikkua. Lowe ym. (2001a) ovat esittäneet, että rakolattialle sijoitetut kumimatot ja kumimattosuikaleet voivat vähentää rakolattian raoista johtuvaa paineen epätasaista jakautumista sorkan eri osille. Siten paineen tasaisempi jakautuminen voi selittää kiinteän lattian ja kumimattoratkaisujen suosiota tavalliseen rakolattiaan verrattuna.

\section{Yhteenveto ja johtopäätökset}

Useimpien kasvatuskokeiden perusteella karsinan pohjamateriaalilla ei ole vaikutusta lihanautojen kasvuun, rehunkäyttöön, rehuhyötysuhteeseen tai ruhon ja lihan laatuun. Lihanaudoilla esiintyy enemmän käyttäytymisongelmia rakolattialla kuin päällystetyillä lattioilla (olkipohja, kumipäällysteet), mikä johtuu rakolattian kovasta ja liukkaasta pinnasta. Erityisesti makuulle asettuminen ja ylös nouseminen vaikeutuvat. Lisäksi rakolattialla eläimet liukastelevat ja voivat jopa vältellä tasapainoa vaativia toimintoja.

Yleisesti lihanaudoilla näyttäisi olevan enemmän terveysongelmia rakolattialla kuin muilla lattiamateriaaleilla. Häntävauriot, ontuminen ja polvinivelien kasvuhäiriöt vaivaavat lihanautoja useammin rakolattialla kuin olkipohjalla. Ontuminen ja kasvuhäiriöt näyttäisivät kuitenkin olevan ongelma myös vinolla pohjalla. Jalkaongelmien vähentämiseksi Euroopan komissio suositteleekin vinopohjan kaltevuudeksi korkeintaan 10 prosenttia (European Commission 2001), mikä vastaa myös suomalaisia suosituksia. Pehmeällä alustalla sorkat eivät kulu yhtä paljon kuin kovemmalla alustalla ja voivat sen seurauksena kasvaa pitkiksi. Kiinteällä lattialla ongelmia aiheuttaa lattialle kerääntyvä liete, joka voi syövyttää sorkkaa ja aiheuttaa bakteeritulehduksen ihoon.

Preferenssikokeissa naudat ovat selvästi osoittaneet, että ne makaavat mieluummin pehmeällä kuin kovalla alustalla. Tämä on ymmärrettävää, koska naudat ovat alun perin sopeutuneet makaamaan joustavalla alustalla luontaisessa elinympäristössään, ruohotasangolla. Preferenssikokeiden perusteella rakolattia on lihanautojen mielestä kaikkein epämiellyttävin pohjamateriaali, jota eläimet todennäköisesti karttavat sen liukkauden ja kovuuden vuoksi. Pehmeä alusta sen sijaan tarjoaa sorkalle pitävämmän pohjan ja vartalon muotoja mukailevan pinnan eläimen maatessa.

Tutkimustulosten perusteella lihanautojen hyvinvointia voidaan parantaa tarjoamalla niille mahdollisuus maata pehmeällä alustalla. Tämä voidaan toteuttaa kuivittamalla osa karsinasta makuualueeksi tai vaihtoehtoisesti päällystämällä osa palkeista kumipäällysteellä. Kiinteitä lattioita ja kuivikkeita käytettäessä lattian puhdistuksesta ja kuivikkeiden riittävästä käytöstä on tärkeää huolehtia eläinten puhtauden ja sorkkaterveyden vuoksi. Sorkkien kasvun hillitsemiseksi karsinaan tulisi sijoittaa myös kovapohjaisia alueita. Rakolattiaa käytettäessä rakojen leveys ei saisi ylittää Suomen eläinsuojelusäädöksissä esitettyjä suosituksia (Taulukko 1). Jalkaterveyden parantamiseksi rakojen leveys voisi olla suosituksiakin kapeampi. 


\section{Kirjallisuus}

Andersen, H. R., Krohn, C. C., Foldager, J., Munksgaard, L. \& Klastrup, S. 1991. Influence of housing and feeding on behaviour, feed intake, growth and carcass and meat quality. Beretning fra Statens Husdyrbrugsforsøg. No. 700. Denmark, Foulum: Statens Husdyrbrugsforsøg. 39 s.

Andreae, U. \& Smidt, D. 1982. Behavioural alterations in young cattle on slatted floors. Hohenheimer Arbeiten 121: 51-61.

Boxberger, J. 1983. Wichtige Verhaltensparameter von Kühen als Grundlage zur Verbesserung der Stalleinrichtung. Habilitation, Weihenstephan.

Drolia, H., Luescher, U. A. \& Meek, A. H. 1990. Tail-tip necrosis in Ontario feedlot cattle: two case-control studies. Prev. Vet. Med. 9: 195-205.

Dumelow, J. 1993. Unbedded self cleaning sloped floors as alternatives to fully slatted floors for beef cattle housing. Teoksessa: Collins, E. \& Boon, C. (toim.). Livestock environment IV. Proceedings of a conference held in Coventry, UK, 6-9 July 1993. St. Joseph: American Society of Agricultural Engineers. s. 209-216.

Dämmrich, K. 1974. Adaptationskrankheiten des Bewegungsapparates bei Masttieren. Fortschritte der Veterinärmedizin 20: 69-80.

European Commission. 2001. The welfare of cattle kept for beef production. Scientific Committee on Animal Health and Animal Welfare. Saatavissa internetistä: http://europa.eu.int/comm/food/fs/sc/scah/out54_en.pdf

Gottardo, F., Ricci, R., Fregolent, G., Ravarotto, L. \& Cozzi, G. 2003. Welfare and meat quality of beef cattle housed on two types of floors with the same space allowance. Italian J. Anim. Sci. 2: 243-253.

Graf, B. 1979. Spaltenbodenhaltung bei Mastochsen. Landbaufororschung Völkenrode, Sonderheft 48: 73-88.

Haidn, B. 1987. Ermittlung von Massen der Klauensohle bei Mastbullen zur Gestaltung tiergerechter Schlitzweiten von Spalteboden. KTBL-Schrift 319: 107-119.

Herlin, A. H. 1997. Comparison of lying area surfaces for dairy cows by preference, hygiene and lying down behaviour. Swedish J. Agric. Res. 27: 189-196.

Hickey, M. C., Earley, B. \& Fisher, A. D. 2003. The effect of floor type and space allowance on welfare indicators of finishing steers. Irish J. Agric. Food Res. 42: 89-100.

Hindhede, J., Sørensen, J. T., Jensen, M. B. \& Krohn C. C. 1996. Effect of space allowance, access to bedding, and flock size in slatted floor systems on the production and health of dairy heifers. Acta Agric. Scand., Sect. A, Animal Sci. 46: 46-53.

Irps, H. 1983. Results of research projects into flooring preferences of cattle. Teoksessa: Baxter, S. H., Baxter, M. R. \& MacCormack, J. A. D. (toim.). Farm animal housing and welfare. Seminar in the CEC Programme of Coordination of Research on Animal Welfare, Aberdeen, Scotland, July 28-30, 1982. Netherlands, The Hague: Martinus Nijhoff. s. 200-215.

Irps, H. 1987. The influence of the floor on the behaviour and lameness of beef bulls. Teoksessa: Wierenga, H. K. (toim.). Cattle housing systems, lameness and behaviour. s. 73-86.

ITEB. 1983. Le taurillon. Paris: I.T.E.B. $230 \mathrm{~s}$.

Jensen, M. B., Krohn, C. C., Hindhede, J. \& Sørensen, J. T. 1995. Resting behaviour of heifers housed in pens with slatted floor, the effect of space allowance and access to a bedded lying area. Teoksessa: Rutter, S. M., Rushen, J., Randle, H. D., Eddison, J. C. (toim.). Proceedings of the 29th International Congress of the International Society for Applied Ethology, Exeter, UK, 3-5 August 1995. Potters Bar, UK: Universities Federation for Animal Welfare. s. 183-184.

Kirchner, M. \& Boxberger, J. 1987. Loading of the claws and the consequences for the design of slatted floor. Teoksessa: Wierenga, H. K. \& Peterse, D. J. (toim.). Cattle housing systems, lameness and behaviour. Proceedings of a seminar on the influence of the design of housing systems for cattle on lameness and on behaviour, Brussels, Belgium, 3-4 June 1986. Dordrecht, Netherlands: Martinus Nijhoff. s. 37-44.

Ladewig, J. 1987. Physiological results of welfare research in fattening bulls. Teoksessa: Schlichting, M. C. \& Smidt, D.J. (toim.). Welfare aspects of housing systems for veal calves and fattening bulls. Proceedings of an EC Seminar, Mariensee, German Federal Rebublic, 16-17 September 1986. Luxembourg: Commission of the European Communities. s. 123-129.

Ladewig, J. 2000. Chronic intermittent stress: a model for the study of long-term stressors. Teoksessa: Moberg, G. B. \& Mench, J. A. (toim.). The biology of animal stress. Basic principles and implications for animal welfare. Oxon, UK: CABI Publishing. s. 159-169.

Lidfors, L. 1992. Behaviour of bull calves in two different housing systems: Deep litter in an uninsulated building versus slatted floor in an insulated building. Report -Institutionen för husdjurshygien. No. 30. Skara: Sveriges Lantbruksuniversitet. $108 \mathrm{~s}$.

Lowe, D. E., Steen, R. W. J. \& Beattie, V. E. 2000. An assessment of lameness in finishing beef cattle accommodated on different floor types over the winter months. Proceedings of the 26th meeting of Irish Grassland and Animal Production Association. s. 151-152.

Lowe, D. E., Steen, R. W. J. \& Beattie, V. E. 2001a. Preferences of housed finishing beef cattle for different floor types. Animal Welfare 10: 395-404. 
Lowe, D. E., Steen, R. W. J., Beattie, V. E. \& Moss, B. W. 1999. The effect of housing system on the behaviour, welfare and performance of beef cattle. Proceedings of the British Society of Animal Science. s. 53.

Lowe, D. E., Steen, R. W. J., Beattie, V. E. \& Moss, B. W. 2001b. The effects of floor type systems on the performance, cleanliness, carcass composition and meat quality of housed finishing beef cattle. Livest. Prod. Sci. 69: 33-42.

Madsen, E. B. 1987. Tail tip inflammation in young fattening bulls on slatted floors. Teoksessa: Schlichting, M. C. \& Smidt, D. (toim.). Welfare aspects of housing systems for veal calves and fattening bulls. Proceedings of an EC Seminar, Mariensee, German Federal Rebublic, 16-17 September 1986. Luxembourg: Commission of the European Communities. s. 131-138.

Manninen, E., de Passillé, A. M., Rushen, J., Norring, M. \& Saloniemi, H. 2002. Preferences of dairy cows kept in unheated buildings for different kind of cubicle flooring. Appl. Anim. Behav. Sci. 75: 281-292.

Ming, J. 1984. Untersuchungen über die eignung von Loch- und Spalteboden (Betonflächenroste) in der Rindviehmast. Diplomarbeit, ETH, Zürich, Switzerland.

MMMA 7.6.1996/396. Eläinsuojeluasetus. Annettu Helsingissä 7.6.1996. Suomen säädöskokoelma 396/1996: 1019-1028.

MMMA 3.6.2002/6/EEO/2002. Maa- ja metsätalousministeriön asetus nautojen pidolle asetettavista eläinsuojeluvaatimuksista annetun maa- ja metsä-talousministeriön päätöksen muuttaminen. Annettu Helsingissä 3.6.2002. Päivitetty: 6/2002. Viitattu: 3.5.2003. Saatavissa internetistä: http://www.mmm.fi/el/laki/F/f20m1fi.pdf

MMMp 23.5.1997/14/EEO/1997. Maa- ja metsätalousministeriön päätös F20 Nautojen pidolle asetettavat eläinsuojeluvaatimukset. Annettu Helsingissä 23.5.1997. Päivitetty: 6/1997. Viitattu: 3.5.2004. Saatavissa internetistä: http://www.mmm.fi/el/laki/F/f20.html

Mossberg, I. 1992. Environmental influences on growing bulls in two housing systems. Rapport -Institutionen for husdjurens utfodring och vard. No. 217. Uppsala, Sweden: Swedish University of Agricultural Sciences. 119 s.

Mossberg, I., Lindell, L., Johnsson, S. \& Tornquist, M. 1993. Insulated and uninsulated housing systems for growing bulls fed grass silage ad libitum. Acta Agric. Scand., Sect. A, Animal Sci. 43: 107-115.

Mossberg, I., Lindell, L., Johnsson, S., Törnquist, M. \& Engstrand, U. 1992. Two housing systems for intensively reared bulls slaughtered in two weight ranges. Acta Agric. Scand., Sect. A, Animal Sci. 42: 167-176.

Murphy, P. A., Hannan, J. \& Monaghan, M. 1987. A survey of lameness in beef cattle housed on slats and on straw. Teoksessa: Wierenga, H. K. \& Peterse, D. J. (toim). Cattle housing systems, lameness and behaviour. Proceedings of a seminar on the influence of the design of housing systems for cattle on lameness and on behaviour, Brussels, Belgium, 3-4 June 1986. Dordrecht, Netherlands: Martin Nijhoff. s. 67-72.

Ruis-Heutinck, L. F. M., Smits, M. C. J., Smits, A. C. \& Heeres, J. J. 2000. Effects of floor type and floor area on behaviour and carpal joint lesions in beef bulls. Teoksessa: Blokhuis, H. J., Ekkel, E. D., Wechsler, B. (toim.). Improving health and welfare in animal production. Proceedings of sessions of the EAAP commission on animal management and health, the Hague, the Netherlands, 21-24 August 2000. Wageningen, Netherlands: Wageningen Pers. s. 29-36.

Schrader, L., Roth, H-R., Winterling, C., Brodmann, N., Langhans, W., Geyer, H. \& Graf, B. 2001. The occurrence of tail tip alterations in fattening bulls kept under different husbandry conditions. Animal Welfare 10: 119-130.

Smits, A. C., Plomp, M., Goedegebuure, S. A. \& Smits, M. C. J. 1994. Behaviour and health of bulls on concrete and rubber topped slatted floors. 45th annual meeting of the European Association for Animal Production, Edinburgh, UK, 5-8 September, 1994. Conference proceedings. Penicuik UK: EAAP 1994 Secretariat. s. 205.

Smits, A. C. \& Wierenga, H. K. 1991. The influence of floor systems on behaviour of veal calves. KTBLSchrift 344: 140-149.

Sundrum, A. \& Rubelowski, I. 2001. The meaningfulness of design criteria in relation to the mortality of fattening bulls. Acta Agric. Scand., Sect. A, Animal Sci., Suppl. 30: 48-52.

Unselm, J., Andreae, U. \& Smidt, D. 1982. Biochemische Parameter im Rahmen tierschutz- und nutzungsbezogener Untersuchungen beim Rind. Fortschritte der Veterinärmedizin 35: 220-225. 